\title{
APOIO MATRICIAL COMO ESTRATÉGIA DE ORDENAÇÃO DO CUIDADO EM SAÚDE MENTAL
}

\author{
THE MATRIX SUPPORT AS A MENTAL HEALTH \\ CARE MANAGEMENT STRATEGY
}

\author{
Marlene Costa Lima ${ }^{1}$ iD [0000-0002-6887-6653], Tonantzin Ribeiro Gonçalves ${ }^{2}$ iD [0000-0003-0249-3358] \\ ${ }^{1}$ Prefeitura Municipal de Imperatriz, Secretaria Municipal da Saúde, Imperatriz, Maranhão, Brasil. \\ $<$ marlenecostalima50@gmail.com> \\ ${ }^{2}$ Universidade do Vale do Rio dos Sinos, Programas de Pós-Graduação em Psicologia e em Saúde \\ Coletiva, São Leopoldo, Rio Grande do Sul, Brasil.
}

Resumo $\mathrm{O}$ estudo do tipo qualitativo e transversal, com o objetivo de analisar a perspectiva dos profissionais dos centros de atenção psicossocial acerca do apoio matricial como estratégia de cuidado psicossocial em saúde mental. Foram utilizadas dez entrevistas semiestruturadas com profissionais de serviços de saúde mental do município de Imperatriz, Maranhão. Depreendeu-se que esses profissionais compreendem o apoio matricial como ferramenta indispensável para a organização do cuidado psicossocial, mas este ainda é utilizado de modo incipiente no seu cotidiano de trabalho ante os desafios relativos à: coexistência do modelo psicossocial com o biomédico; falta de condições de trabalho; falta de educação continuada e permanente da rede de atenção; burocratização e verticalização das ações da gestão; e motivação para o trabalho entre as equipes. Algumas vivências exitosas de apoio matricial para esses trabalhadores resultaram da cogestão dos processos de trabalho entre profissionais e usuários. Recomenda-se que haja um claro direcionamento do trabalho por parte da gestão, com a definição de uma equipe de matriciadores e um planejamento para sua realização, construindo processos de trabalho que favoreçam tal prática.

Palavras-chave apoio matricial; sistemas de apoio psicossocial; serviços de saúde mental.

\begin{abstract}
The present qualitative and cross-sectional study has the aim of analyzing the perspective of the professionals of the psychosocial care centers regarding the matrix support as a psychosocial care strategy in mental health. We used ten semi-structured interviews with mental health service professionals from the municipality of Imperatriz, in the state of Maranhão, Brazil. We concluded that these professionals understand matrix support as an indispensable tool to organize psychosocial care, but it is still used incipiently in their everyday practice regarding the following challenges: coexistence of the psychosocial and biomedical models; lack of work conditions; lack of permanent and ongoing education in the care network; bureaucratization and verticalization of the management actions; and motivation to work on the part of the teams. Some successful experiences regarding matrix support for these workers resulted from the co-management of work processes between professional and users. We recommend that there be a clear direction of the work on the part of the management, with a definition of a team of matrix workers and a planning for its development, creating work processes that favor such a practice.
\end{abstract}

Keywords matrix support; psychosocial support systems; mental health services. 


\section{Introdução}

A saúde mental é um problema de saúde pública global, em razão do ônus que causa não só ao portador de sofrimento psíquico mas também aos seus familiares e comunidades interligadas, como empresas, escolas e sistemas de saúde (World Health Organization - WHO, 2017). Segundo relatório da Comissão de Saúde Mental Global e Desenvolvimento Sustentável da revista Lancet, a carga global de doença atribuível aos problemas mentais cresceu em todos os países nos últimos anos (Patel et al., 2018). Embora cada região ou país possua especificidades socioculturais, estima-se que, até 2015 , 322 milhões de pessoas no mundo sofriam de depressão, 264 milhões de transtorno de ansiedade e 700 milhões de algum transtorno mental (WHO, 2017). Assim, entende-se que são essenciais a ampliação e a qualificação da oferta de serviços de saúde mental nos sistemas de saúde com cobertura universal, bem como sua integração com outras prioridades de saúde global (Patel et al., 2018).

No Brasil, estima-se que a prevalência de transtornos mentais na população adulta está entre $20 \%$ e $56 \%$, acometendo principalmente mulheres e trabalhadores (Santos e Siqueira, 2010). Nesse sentido, o país tem procurado avançar, sustentado por um aparato legal (Brasil, 2001), construído mediante a organização dos trabalhadores da saúde num movimento que ficou conhecido como Reforma Psiquiátrica (Jorge et al., 2011). A reforma provocou fortes mudanças na forma de cuidar dos transtornos mentais e compreendê-los, fundamentando-se numa proposta de desinstitucionalização que busca substituir o paradigma biomédico e hospitalocêntrico pelo cuidado comunitário e articulando-se com a atenção primária à saúde (APS) (Brasil, 2016).

Propõe-se, portanto, uma mudança nos processos de cuidado em saúde mental, mediante a compreensão da gestão da clínica, numa perspectiva psicossocial. Essa nova clínica, referida como ampliada, é incorporada pela Política Nacional de Humanização (Brasil, 2010) tendo como diretrizes: a disponibilização de diversos saberes ao usuário de forma integrada; a construção compartilhada de diagnósticos por profissionais de diferentes formações; a responsabilização dos profissionais com o usuário e não com o diagnóstico, tomando-o de modo ativo no seu tratamento; privilégio de técnicas relacionais, grupais e integrativas; a inclusão do profissional de saúde como parte do cuidado.

Nesse contexto, o apoio matricial construiu-se como uma ferramenta importante para fortalecer o cuidado na perspectiva psicossocial. O apoio matricial é uma estratégia de organização de trabalho entre equipes de saúde baseada na ideia de cogestão e do suporte técnico especializado para a atenção primária em saúde (APS) (Minozzo e Costa, 2013). A definição de apoio matricial tem origem em discussões sobre a organização do trabalho em saúde em 1999 (Campos e Domitti, 2007) e foi formalizada com a criação 
dos Núcleos de Apoio à Saúde da Família (Nasfs), pela portaria n. 154/2008 (Brasil, 2008). Desde então, o Nasf passou a ser o personagem principal do apoio matricial, prerrogativa estendida aos profissionais de centros de apoio psicossocial (CAPSs), no que concerne aos transtornos mentais.

Os CAPSs constituem-se como um dispositivo de atenção à saúde mental voltado para promover a inserção social das pessoas em sofrimento psíquico por meio de ações intersetoriais e interdisciplinares (Brasil, 2008). Na saúde mental, o apoio matricial busca ordenar o cuidado psicossocial numa lógica territorial, rompendo com práticas burocratizadas. De forma pedagógica, procura habilitar os serviços de saúde para o acolhimento das demandas de saúde mental, possibilitando a troca de saberes, a organização dos fluxos na rede de atenção à saúde e das ações no território (Pinto et al., 2012; Minozzo e Costa, 2013; Jorge et al., 2015; Oliveira e Campos, 2015; Bispo Júnior e Moreira, 2018; Viana e Campos, 2018).

$\mathrm{O}$ apoio matricial se constitui como uma metodologia para realizar a gestão em atenção em saúde possibilitando a redução da fragmentação do cuidado, tão enraizado na prática dos profissionais da área (Campos e Domitti, 2007). Assim, pode ser definido como a produção de um cuidado colaborativo entre duas ou mais equipes de saúde de forma compartilhada (Chiaverini, 2011). Segundo Oliveira e Campos (2015), o trabalho interprofissional aparece com a nomenclatura de cuidado compartilhado ou cuidado colaborativo na literatura internacional, mas o termo apoio matricial, na sua dimensão conceitual ou metodológica é singular no Brasil. Observa-se que isto se dá de forma diferenciada em cada país em decorrência das peculiaridades dos seus sistemas de saúde (Kelly et al., 2011), embora a busca por uma metodologia que favoreça resolutividade do cuidado em saúde seja comum entre vários estudos (Foy et al., 2010; Pinto et al., 2012; Viana e Campos, 2018).

A maior parte das pesquisas sobre apoio matricial na literatura brasileira foca a perspectiva dos profissionais da APS (Bonfim et al., 2013; Iglesias e Avellar, 2014), sendo escassos os estudos abordando os profissionais dos CAPSs. Entende-se que é de relevância dar voz a esses profissionais que trabalham no dispositivo gerenciador do cuidado de saúde mental, a fim de informar as políticas públicas. Em especial, ainda se salienta a escassez de estudos que enfoquem a sistematização da prática em saúde com base no recorte regional do Norte do país (Costa, Colugnati e Rozani, 2015; Pinho, Souza e Esperidião, 2018). Em acréscimo, a articulação do apoio matricial realizado pelos CAPSs na APS é um dos 23 indicadores e metas para 2017-2021 do Pacto Interfederativo 2016 no Brasil (Distrito Federal, 2016), respaldado pela Carta das Nações Unidas (Brasil, 2005). Apesar disso, a Política Nacional de Saúde Mental vem sofrendo uma série de retrocessos desde dezembro de 2017, imposta por um contexto político de desmonte da rede substitutiva (Sousa e Jorge, 2019). Diante desse cenário, o presente estudo buscou compreender a perspectiva 
dos profissionais de CAPS acerca do apoio matricial como estratégia de cuidado psicossocial em saúde mental.

\section{Percurso metodológico}

Trata-se de um estudo de natureza qualitativa, exploratório e de corte transversal. A coleta de dados foi realizada na cidade de Imperatriz (MA) entre abril e agosto de 2018. Nos últimos anos, a cidade tornou-se um polo universitário, comercial e de serviços de saúde, recebendo em torno de 700 mil pessoas de cidades vizinhas dos estados do Maranhão, Pará e Tocantins (Imperatriz, 2018). O município dispõe de uma rede de saúde mental composta por um CAPS III, um CAPS AD, um CAPS IJ, um serviço de residência terapêutica, um ambulatório de saúde mental, um consultório de rua, serviços de urgência e emergência, cinco equipes de Nasf e 28 equipes de Estratégia Saúde da Família (ESF) (Brasil, 2018).

Participaram do estudo dez profissionais de nível superior dos CAPSs, que tinham mais de dois anos de trabalho na saúde mental e não estavam em desvio de função. Os participantes contemplaram os diversos serviços de saúde mental da cidade (CAPS III, AD III e IJ), uma diversidade de profissões, sendo comum a todos o vínculo de trabalho estatutário e o perfil de uma formação específica em saúde mental. Dentre os participantes, sete eram mulheres e três homens, identificados por uma numeração de 1 a 10 antecedida pelo símbolo \# (Quadro 1).

Quadro 1

\begin{tabular}{|c|c|c|c|c|c|}
\hline \multicolumn{6}{|c|}{ Dados gerais sobre os profissionais de saúde mental $(n=10)$} \\
\hline Participantes & Idade & Sexo & Profissão & Tempo de serviço & Formação \\
\hline$\# 1$ & 33 & $\mathrm{~F}$ & Assist. social & 5 anos & $\begin{array}{l}\text { Esp. saúde mental/saúde da família/ } \\
\text { gestão da clínica }\end{array}$ \\
\hline \#2 & 28 & $\mathrm{~F}$ & Ed. físico & 5 anos & $\begin{array}{l}\text { Cursos de aperfeiçoamento em } \\
\text { saúde mental }\end{array}$ \\
\hline \#3 & 58 & $\mathrm{~F}$ & Pedagogo & 10 anos & $\begin{array}{l}\text { Especialista em saúde mental/ } \\
\text { educação inclusiva/ gestão da clínica }\end{array}$ \\
\hline \#4 & 43 & $\mathrm{~F}$ & Psicólogo & 16 anos & $\begin{array}{l}\text { Especialista em álcool e outras } \\
\text { drogas/mestre em saúde coletiva }\end{array}$ \\
\hline \#5 & 39 & M & Médico & 10 anos & Especialista em saúde mental \\
\hline \#6 & 52 & M & Enfermeiro & 16 anos & Especialista em saúde mental \\
\hline \#7 & 34 & $\mathrm{~F}$ & Enfermeira & 11 anos & $\begin{array}{l}\text { Especialista em saúde mental/ } \\
\text { Estratégia da Família }\end{array}$ \\
\hline$\# 8$ & 36 & $\mathrm{~F}$ & $\begin{array}{l}\text { Psicólogo/ } \\
\text { psicanalista }\end{array}$ & 14 anos & Especialista em saúde mental \\
\hline$\# 9$ & 39 & $M$ & $\begin{array}{c}\text { Médico } \\
\text { psiquiatra }\end{array}$ & 13 anos & $\begin{array}{l}\text { Especialista em saúde mental/ } \\
\text { Psiquiatria }\end{array}$ \\
\hline$\# 10$ & 31 & $\mathrm{~F}$ & Psicóloga & 3 anos & $\begin{array}{l}\text { Especialista em saúde mental e } \\
\text { neuropsicopedagogia }\end{array}$ \\
\hline
\end{tabular}


As entrevistas duraram, em média, duas horas e seguiram um roteiro semiestruturado, a fim de apreender a perspectiva do sujeito entrevistado e colher com profundidade sua narrativa. O roteiro das entrevistas cobria a trajetória e vivências de trabalho dos profissionais, suas concepções e experiências de cuidado em saúde mental e sobre o apoio matricial. A pesquisadora ainda coletou informações gerais sobre os participantes e manteve um diário de campo no qual registrou suas impressões quanto às entrevistas.

Quanto aos aspectos éticos, esta pesquisa seguiu as recomendações para a realização de estudos com seres humanos, de acordo com a resolução n. 466/2012 do Conselho Nacional de Saúde (Brasil, 2012). O projeto foi submetido ao Comitê de Ética em Pesquisa da Universidade do Vale do Rio dos Sinos com o parecer n. 2.549824. Todos os participantes foram esclarecidos sobre os propósitos da pesquisa e assinaram o termo de consentimento livre e esclarecido.

Foi empregada a análise temática de conteúdo (Bardin, 2009; Minayo, 2010), que possibilita a organização dos dados e o entendimento de significados e vivências em torno do fenômeno. Inicialmente, após a escuta de todos os áudios e leitura geral de todo o material, identificaram-se as ideias centrais (Bardin, 2009). Em seguida, realizou-se uma categorização inicial dos relatos com o intuito de construir uma lógica dos conteúdos apresentados nos dados. Por fim, formulou-se a categorização final, realizando o relato e a interpretação dos dados, discutindo-os à luz da conceitualização do apoio matricial e dos achados de outros estudos (Minayo, 2010).

Construiu-se uma categoria central que buscou descrever a relação entre a compreensão dos trabalhadores de CAPS sobre o cuidado psicossocial e o apoio matricial, bem como compreender a perspectiva dos profissionais de CAPS acerca do apoio matricial como estratégia de ordenação do cuidado psicossocial em saúde mental. A seguir, apresentam-se as quatro subcategorias que a compõem: percepções sobre o cuidado psicossocial; compreensão do apoio matricial; influência do apoio matricial na atuação do profissional; organização do trabalho para o apoio matricial.

\section{Compreensão dos profissionais de CAPS sobre cuidado psicossocial}

De modo geral, os profissionais relataram diversos aspectos que, na sua concepção, caracterizavam o cuidado psicossocial, tais como a atenção em rede, o trabalho em equipe, a necessidade de centralizar as ações nos usuários e a integralidade do cuidado. Dentre as principais unidades de sentido da subcategoria (Quadro 2), os profissionais também descreveram experiências exitosas que os influenciavam nessa percepção e identificaram desafios para consolidar o cuidado psicossocial. 
Quadro 2

Compreensão do cuidado psicossocial em saúde

\begin{tabular}{|l|l|}
\hline Temas centrais & Unidades de sentido \\
\hline \multirow{4}{*}{ Definição psicossocial do cuidado } & $\begin{array}{l}\text { Condução diária a partir da necessidade do usuário } \\
\text { Envolve intervenção no campo da clínica ampliada } \\
\text { Cuidado em rede }\end{array}$ \\
& $\begin{array}{l}\text { Disponibilidade para estar com o outro em sofrimento psíquico } \\
\text { Atendimento integrado, em equipe } \\
\text { Experiências exitosas vinculadas à vivência } \\
\text { do trabalho em rede }\end{array}$ \\
& $\begin{array}{l}\text { Atenção especial à saúde do profissional cuidador } \\
\text { Serviços e profissionais mobilizados para ajudar o usuário } \\
\text { Atendimento em equipe } \\
\text { Apoio matricial na coordenação do cuidado }\end{array}$ \\
\hline Fonte: As autoras. &
\end{tabular}

Fonte: As autoras

O paradigma psicossocial em saúde mental advoga um cuidado centrado na pessoa em seu contexto comunitário e social e não na doença (Pinto et al., 2012). Nesse sentido, os CAPSs são uma das principais estratégias para operacionalizar esse rompimento, ao propor mudar a relação entre profissional, doença e usuário. Apesar disso, a lógica manicomial ainda parece vigorar no cotidiano do serviço.

Infelizmente, o serviço, ele ainda reproduz práticas lá do hospital psiquiátrico, práticas manicomiais, tipo o usuário vem para a consulta, pega a receita, vai embora, o usuário tem a hora de tomar o remédio, o usuário tem um jeito de tomar o remédio, tem a hora da comida. Então assim, eu acho que, infelizmente, ainda no CAPS III a gente ainda tem essa reprodução de práticas de dentro do manicômio (\#7).

Embora não tenham feito menção especificamente a tais práticas, os demais entrevistados relataram lacunas na sua capacidade pessoal ou da equipe em atender à complexidade do cuidado psíquico, confirmando outros achados (Pinho, Souza e Esperidião, 2018). Essa ideia se confirmou em oito dos relatos, demonstrando certa ambiguidade que fragilizava a intervenção psicossocial, já que, por um lado, apontava para a impotência sentida pelos profissionais diante da complexidade de algumas situações de cuidado e, por outro, para a importância de um trabalho interdisciplinar e integrado como uma prática necessária na busca de resolutividade das demandas do usuário (Anjos Filho e Sousa, 2017).

Foi o caso inclusive multiprofissional, porque ele [paciente] não sabia fazer geladão [picolé]. Então alguém aqui ensinou a parte culinária, aí aprendeu a fazer serviços gerais, lavando ambulância, aí depois colocaram ele em uma oficina mecânica e ele aprendeu a fazer retífica de motores e hoje trabalha em uma oficina. Passou a ser atendido no ambulatório, faz a troca de receita e segue a vida dele (\#6). 
Como evidencia o relato, a evolução do paciente se ligava a sua inserção no mercado de trabalho, a qual conseguiu com o auxílio da equipe multiprofissional. Porém, a continuidade do cuidado do usuário no CAPS mantinha-se apenas pela busca da medicação. Verifica-se, portanto, que os pressupostos biomédicos e psicossociais estavam presentes de modo concomitante no cotidiano dos processos de trabalho. Diante disso, o desafio de consolidar o cuidado psicossocial se torna problemático ao se considerar um cenário de recrudescimento da luta antimanicomial na política nacional, marcado por decisões na esfera federal, como a inclusão dos hospitais psiquiátricos como parte da rede de assistência psicossocial (Sousa e Jorge, 2019). Tal cenário parecia já afetar os profissionais entrevistados, pois, durante o trabalho de campo, muitos relataram estar passando por mudanças abruptas nas equipes, com alterações não pactuadas na rotina de trabalho.

A resistência da rede em atender e acolher usuários da saúde mental também é um ponto que já foi apontado por outros autores como um dos obstáculos para o avanço da metodologia do apoio matricial (Oliveira e Campos, 2015). No relato a seguir, um entrevistado ilustra a gravidade a que tais barreiras podem levar.

Eu acho que faltou o colega lá fazer uns exames básicos, um exame de sangue. Porque quando chega um paciente que a gente encaminha de lá [hospital], já chega: "não, é paciente do CAPS". Só que não existe paciente do CAPS, existe paciente da rede de saúde do SUS [Sistema Único de Saúde], aí eu passo... o paciente passou três dias lá no HMI [Hospital Municipal de Imperatriz], não fizeram um hemograma do paciente. Poderia ter sido feito. E quando voltou para mim eu estava no CAPS $\mathrm{AD}$, eu atendi ele muito rápido e mandei para o CAPS III e ficou lá. Eu não podia ter feito isso, eu tinha que ter mandado de volta para o HMI. Infelizmente, o paciente veio a óbito (\#5).

Os profissionais entrevistados salientaram também as carências estruturais e de qualificação de recursos humanos como obstáculos diários a serem enfrentados.

Eu vejo ainda os serviços lutando por coisas tão básicas, tão básicas, tão fundamentais para o serviço funcionar, e aí por mais que eu compreenda que o trabalho em saúde seja um trabalho autônomo, que a gente tem um empoderamento do nosso trabalho e que se a gente ficar reclamando a gente nunca vai andar, porque sempre vai faltar alguma coisa. Por outro lado também, você ficar batalhando e tentando convencer de que tem que ter comida, se funcionário pode ou não pode comer, ou seja, são coisas absurdas, entende? (\#4). 
Apesar da precarização das condições de trabalho, nove dos entrevistados atribuíram ao apoio da equipe, da rede ou ao apoio matricial as experiências exitosas e a resolutividade dos atendimentos. Para esses profissionais, a gestão do cuidado psicossocial exigia o rompimento da lógica manicomial num processo que envolvia a reflexão de cada profissional e também a transformação dos processos de trabalho da equipe e dos gestores:

“A clínica da dependência ela é muito difícil, ela é muito complexa, ela é muito desafiadora, isso exige muito do profissional, porque a gente precisa estar constantemente repensando o trabalho, repensando o que fazer..." (\#8).

Nesse sentido, considera-se que a saúde mental traz especificidades para o trabalho em saúde por envolver lidar constantemente com o sofrimento psíquico e com a concepção do cuidado em saúde mental como um construto social, marcado por aspectos culturais, sociais e econômicos (Jorge et al., 2015). Tal definição coaduna-se com a compreensão dos entrevistados, os quais descreveram o cuidado em saúde mental como envolvendo várias dimensões do indivíduo, sendo quase inevitável essa visão ao lidar com usuários, indicando uma noção de cuidado alinhada aos princípios da integralidade (Pinho, Souza e Esperidião, 2018).

É uma construção diária, e às vezes aquilo que funciona hoje para um usuário amanhã não funciona, então acredito que no cuidado na saúde mental a gente tem que estar buscando conhecimento, se reinventando, tendo criatividade na prática e tendo compromisso de acolher o usuário como um indivíduo, que ele não é apenas paciente. Assim, a saúde mental ela tem toda uma questão social antes, toda uma questão familiar que às vezes colabora para o adoecimento mental... (\#1).

Nas outras áreas eu não vejo que o médico ele tem assim um contato, realmente, mais, digamos assim, quando você atende, você é dermatologista, você atende a pele do paciente, quando você é cirurgião você vai operar a barriga, fazer alguma coisa, mas quando você está atendendo a mente parece que você está realmente atendendo o paciente, a pessoa por inteiro (\#5).

O relato de \#5 destaca a possibilidade de se acolher a pessoa e não a doença como uma característica própria da saúde mental em relação às outras áreas da saúde. Porém, tal posição pode gerar um distanciamento entre profissionais de serviços diferentes. Por exemplo, no estudo realizado por Prata e colaboradores (2017), os profissionais da APS percebiam que a área da saúde mental se isolava e criava um sistema próprio que dificultava o diálogo. Assim, seria importante 
desconstruir uma suposta hierarquia entre serviços e profissionais de áreas diferentes, facilitando, justamente, a construção conjunta de entendimentos comuns que levem em conta a integralidade no processo saúde-doença.

A análise crítica dos relatos dos profissionais, protagonistas da consolidação do paradigma psicossocial, revelou haver uma composição multiprofissional de pessoal com baixo grau de coordenação, alto nível de queixas, pouca integração entre as distintas especialidades e os demais serviços da rede. As dificuldades gerenciais, aliadas à cultura de exclusão e asilamento herdada pelos trabalhadores de CAPS, dificultava a implantação de intervenções como o apoio matricial; ao mesmo tempo, a disponibilidade para o trabalho em equipe, o reconhecimento da perspectiva do cuidado integral e da clínica ampliada, valorizando a escuta e o vínculo (Merhy et al., 2014), eram fatores que favoreciam o apoio matricial como prática cotidiana.

\section{Compreensão do apoio matricial}

Os relatos evidenciaram a existência de diferentes perspectivas sobre o apoio matricial entre os profissionais, ora como estratégia de ordenação do cuidado em saúde mental, ora como mais uma das tarefas ou ações que deveriam ser desempenhadas. O quadro 3 mostra os pontos centrais levantados pelos relatos dos profissionais nessa subcategoria.

Quadro 3

Compreensão de apoio matricial
\begin{tabular}{|l|l|}
\hline Temas centrais & Unidades de sentido \\
\hline $\begin{array}{l}\text { Entendimento vinculado à } \\
\text { ideia de capacitação }\end{array}$ & $\begin{array}{l}\text { Especialista da saúde mental que vai subsidiar os profissionais da atenção básica, } \\
\text { como o Nasf e o próprio CAPS. }\end{array}$ \\
\hline Entendimento vinculado à ideia & $\begin{array}{l}\text { Realização de atendimentos, orientações e consultas conjuntas. } \\
\text { Nova forma de fazer saúde envolvendo mais de uma equipe de saúde; construção } \\
\text { de um cuidado em rede. } \\
\text { trabalho em equipe ou em rede } \\
\text { terapêutico do paciente. } \\
\text { Suporte técnico pedagógico a outros profissionais da saúde mental. } \\
\text { Trabalho desenvolvido juntamente com a atenção básica com base na discussão } \\
\text { de caso. } \\
\text { Práticas integrativas de cuidado entre os dispositivos da atenção básica e saúde } \\
\text { mental. }\end{array}$ \\
\hline Desconhecimento & Muito complicado. \\
\hline Fonte: As autoras.
\end{tabular}

Nasf: Núcleo de Apoio à Saúde da Família; CAPS: Centro de Atenção Psicossocial.

Dos dez participantes, oito concebiam o apoio matricial como uma estratégia de intervenção no trabalho em equipe ou em rede: “Uma es- 
tratégia, a qual, vários profissionais, de diferentes serviços, vão se unir para tentar contribuir com o paciente" (\#10). Nessa direção, o apoio matricial em saúde mental se apresenta como "uma proposta de mudança do arranjo organizacional e das responsabilidades profissionais e gerenciais, de modo a facilitar a cogestão em locais onde é necessário um trabalho em equipe" (Campos et al., 2014, p. 988).

Na concepção de \#2, \#6 e \#8, o apoio matricial pressupõe uma equipe especializada em saúde mental que, com seu núcleo de saber específico, irá conjuntamente matriciar as equipes da APS, consideradas como equipe de referência (Campos e Domitti, 2007; Bonfim et al., 2013).

É ajudar os profissionais que não estão conseguindo trabalhar em algum caso por meio de um suporte, ir ao serviço ou o profissional ir ao nosso serviço (\#2).

O apoio matricial é o especialista que tem conhecimento de alta complexidade, especialista em alguma coisa, no caso da saúde mental ele tem que ser direcionado para a atenção básica (\#6).

É um trabalho desenvolvido junto da atenção básica (\#8).

Alguns entrevistados (\#7, \#3 e \#1) também entendiam o apoio matricial como uma estratégia de efetivação de um cuidado integral. Assim, verifica-se que há, por parte dos profissionais, uma intencionalidade em vislumbrar um cuidado de forma plena, porém se confrontam com redes de cuidado fragilizadas (Pinto et al., 2012).

Uma nova estratégia de atenção, onde equipes estão juntas, por exemplo, equipe de CAPS com a equipe de Estratégia Saúde da Família, com a equipe Nasf, discutindo o projeto terapêutico dos usuários (\#7).

Eu acredito se a atenção básica, a rede de saúde mental e serviços de saúde trabalhassem mais o apoio matricial, a rede estaria mais articulada, seria possível esse usuário, ele ter esse atendimento integral em saúde, o apoio, o atendimento, ele seria compartilhado (\#1).

Para Campos e colaboradores (2014), o apoio matricial envolve corresponsabilização pelos casos e a troca de saberes entre os profissionais e serviços de saúde. Esta concepção do apoio matricial se apresenta como fator essencial para um cuidado integralizado do usuário, como relataram \#9 e \#10: “Uma estratégia que vários profissionais, de diferentes serviços, vão se unir para tentar contribuir com o paciente" (\#10). 
Destaca-se a proximidade entre o relato dos entrevistados e o conceito de apoio matricial, o que é resultado das suas trajetórias profissionais e formativas na área da saúde mental. Porém, essa compreensão teórica pode não se refletir numa prática efetiva de apoio matricial, apesar do fato de todos os profissionais terem passado por capacitação ou curso específico de saúde mental, na perspectiva da Reforma Psiquiátrica. Nesse sentido, uma revisão sistemática alerta que a concretização de um trabalho colaborativo em saúde vincula-se não apenas a uma equipe preparada teoricamente e com experiência na área, mas que seja capaz de desenvolver comunicação adequada e definir claramente os papéis (Kelly et al., 2011).

Os profissionais elencaram uma série de obstáculos que impediam o avanço do apoio matricial, desde questões relativas à gestão até aspectos estruturais dos serviços. O relato de \#5, por exemplo, colocou o apoio matricial como uma estratégia muito complicada, porque a interligação de tantos profissionais e serviços não era operacionalizável. Por sua vez, outro profissional (\#4) mencionou a ideia de apoio matricial como vinculada apenas à capacitação e à divisão de tarefas, e não exatamente ao fazer conjunto.

\section{Influência do apoio matricial na atuação do profissional}

Acredita-se que as experiências dos profissionais com o apoio matricial podem determinar como e se essa estratégia de cuidado e intervenção será efetivamente empregada visando colaborar para a construção de um trabalho coletivo em saúde mental. Nessa subcategoria, buscou-se descrever as vivências de apoio matricial dos trabalhadores no contato direto com a APS e as repercussões do uso dessa estratégia na equipe e neles próprios. O Quadro 4 apresenta os principais conteúdos elencados sobre esse aspecto.

\section{Quadro 4}

Influência do apoio matricial na atuação do profissional

\begin{tabular}{|c|c|}
\hline Temas centrais & Unidades de sentido \\
\hline Impacto no profissional & $\begin{array}{l}\text { Suporte fundamental para não se sentir sozinho diante de casos complexos. } \\
\text { Reduz sensação de impotência e frustração. } \\
\text { Aumenta o aprendizado. } \\
\text { Visualização do resultado do seu trabalho. } \\
\text { Estimula movimento profissional diferenciado; maior conhecimento da rede. }\end{array}$ \\
\hline Impacto na equipe & $\begin{array}{l}\text { Ampliação do trabalho no território. } \\
\text { Melhora qualidade do cuidado. } \\
\text { Mudança na cultura dos profissionais. }\end{array}$ \\
\hline
\end{tabular}

Dos dez profissionais entrevistados, três não tiveram nenhuma vivência de apoio matricial (\#5, \#8 e \#9), portanto, não identificaram repercussões na 
sua própria atuação, mas sim no trabalho da equipe, por esta ter vivenciado experiências esporádicas de apoio matricial ou mesmo porque detinham conhecimentos teóricos. Desses três profissionais, dois eram médicos, o que pode indicar a possibilidade da sobrecarga em atender ao alto nível de medicalização e a falta de tempo para outras atividades que não fossem a consulta e a dispersão de receita. Esses dois profissionais também afirmaram não desenvolver nenhuma ação no território, a não ser, muito raramente, em visitas domiciliares. Isso nos remete a uma dificuldade particular dessa categoria na superação do paradigma biomédico e do distanciamento médico-paciente.

No âmbito da iniciativa do trabalhador, os relatos de \#1, \#6 e \#7 apontaram otimismo quanto à efetividade do apoio matricial, mas destacaram a necessidade de o profissional estar motivado e engajado em protagonizá-lo: "Se você, realmente, tiver disponível e tiver aceitação desse apoio matricial como sendo possível de ele dar certo" (\#6). Esse movimento de protagonismo implica a realização de uma clínica "produto de um coletivo desejante, capaz de resistir aos mecanismos de captura e disciplinarização da vida" (Sundfeld, 2010 , p. 1.079). Os mecanismos de captura passam pela naturalização do sofrimento psíquico aliado às deficiências do serviço público, o que promove no trabalhador uma impotência que o engessa (Sundfeld, 2010) e o distancia das possibilidades de um cuidado psicossocial.

Outro aspecto apontado nas entrevistas foi a compreensão do apoio matricial como um instrumento de aprendizagem na perspectiva de educação permanente. A possibilidade de troca de informações e mesmo o embasamento no conhecimento específico sobre saúde mental que tinham que buscar levavam os profissionais a estudar e se instrumentalizar. Somavam-se a isso as demandas trazidas pelos profissionais matriciados que geravam novas aprendizagens: "Eu vi pessoas estudando, dialogando a respeito da situação, pessoas incluídas, quebrando seus preconceitos, porque o apoio matricial é rico porque faz a gente pensar e a gente pode pensar diferente" (\#4). O apoio matricial como instrumento de formação permanente funda-se na sua dimensão técnico-pedagógica, promovendo ações conjuntas e trocas entre os profissionais. Assim, o apoio matricial tem o potencial de aprimorar o repertório de conhecimentos, os modos de compreender e de fazer dos profissionais (Bispo Júnior e Moreira, 2018).

A melhoria na qualidade do cuidado ao usuário foi um dos desdobramentos percebidos da atuação no apoio matricial pelos entrevistados. Os relatos daqueles que vivenciaram o apoio matricial expunham os impactos positivos dessa estratégia com muita clareza, salientando a significância desse fazer para o seu trabalho, como ilustra a fala de \#1: "Eu acho que o apoio matricial pode garantir a continuidade do cuidado do usuário. Pode não, garante. Então, assim, eu acho que o apoio matricial é o grande lance para a saúde mental." 
Como evidenciam as falas a seguir, as experiências de apoio matricial desses profissionais trouxeram impactos positivos na equipe, fortalecendo a perspectiva psicossocial no atendimento do paciente e impondo o questionamento da permanência de práticas asilares e centradas no serviço.

Amplia a visão da equipe de forma em geral e também no serviço em si ele não fica sobrecarregado com esse atendimento, e a gente pode sair de dentro do CAPS e trabalhar. Amplia esse trabalho no território, o apoio matricial (\#1).

Serve para integrar os conhecimentos e não só para fazer um simples encaminhamento. Você tem que ter aquele cuidado de verificar a situação biopsicossocial do paciente e, se possível, resolver. A questão da resolutividade, resolver na atenção básica para diminuir o fluxo na saúde mental (\#9).

Entende-se que o exercício do apoio matricial permitia mudanças na forma como cada profissional entendia o modelo de atenção e como a equipe podia operacionalizar o cuidado na perspectiva psicossocial. Ao mesmo tempo, vale ressaltar que, ao serem questionados sobre ações desenvolvidas pelos CAPSs no território, os entrevistados relataram atividades como a realização de palestras esporádicas, visitas domiciliares e experiências pontuais de apoio matricial que tiveram a oportunidade de vivenciar. Acredita-se que o baixo investimento em ações de promoção da saúde no SUS, de modo geral, aliado à insuficiência do quantitativo mínimo de profissionais, à precarização das condições de trabalho e à falta de insumos e infraestrutura, resulta em dificuldades dos serviços de transcender ações curativas e reabilitadoras (Bispo Júnior e Moreira, 2018). Somada a experiências vivenciadas na atenção à saúde mental em modelos isolados e tradicionalmente institucionalizados, essa precariedade acaba por sublinhar, no imaginário dos profissionais e dos gestores, o apoio matricial como algo impossível de ser feito, reduzindo o investimento em uma atuação efetiva (Bispo Júnior e Moreira, 2018).

\section{Organização do trabalho para o apoio matricial}

Os entrevistados revelaram que uma diversidade de vivências demarcava distintas propostas para melhor efetivação e organização de um trabalho de 
apoio matricial. O Quadro 5 demonstra que alguns modos de organização focalizavam ações nas quais a equipe tinha mais autonomia para gerenciar, enquanto outras formas indicavam aspectos que dependiam de decisões da gestão.

Quadro 5

Organização do trabalho para o apoio matricial
\begin{tabular}{|l|l|}
\hline Temas centrais & \multicolumn{1}{c|}{ Unidades de sentido } \\
\hline \multirow{5}{*}{ Foco na equipe } & $\begin{array}{l}\text { Terientações gerais entre os serviços, mesmo de forma simples. } \\
\text { Acompanhar o projeto terapêutico singular no usuário no território junto com a atenção } \\
\text { básica. } \\
\text { Colocar-se no lugar do outro e ter comprometimento com o usuário. }\end{array}$ \\
\hline Foco na gestão & $\begin{array}{l}\text { Retomar a função do ativador de rede. } \\
\text { Investir em condições favoráveis de trabalho, estimulando o profissional. } \\
\text { Desburocratizar o trabalho; descentralizar a gestão. } \\
\text { Retomar experiências anteriores, em que cada serviço tinha profissionais de referência para } \\
\text { atender determinada unidade. } \\
\text { Estruturar equipe de profissionais do CAPS responsável pelo apoio matricial. }\end{array}$ \\
\hline
\end{tabular}

CAPS: Centro de Atenção Psicossocial.

De modo geral, os entrevistados enfatizaram que a construção de processos de trabalho em um novo arranjo organizacional centrado no apoio matricial dependia em grande parte da inclusão de ações que favorecessem a participação dos profissionais de CAPS, assim como de um modelo de atenção e de gestão comprometido com os princípios filosóficos e organizativos do SUS. Esse entendimento coaduna-se com os achados de Viana e Campos (2018) em três localidades da região Sudeste, que apontaram como a plena utilização do apoio matricial é fortemente influenciada pelo contexto institucional, pelos modelos de gestão e de atenção. Nesse sentido, a interrupção de ações, a falta de pactuação ou de estímulo direto na gestão dos processos de trabalho pode gerar desconfiança nos trabalhadores quanto ao modelo de atenção a ser adotado. Para os profissionais, o êxito do apoio matricial dependia de haver canais para a cogestão do trabalho.

Eu acredito que se a gestão, a coordenação, ela tiver uma visão adequada do que é o cuidado em saúde mental, clínica ampliada, apoio matricial, ela coloca isso para funcionar, ela estimula a equipe, ela cobra da equipe, ela faz junto com a equipe, mas se não tiver essa visão, a equipe muitas vezes pode até ficar estagnada (\#1).

Então na gestão passada eles fizeram, teve esse pontapé, e hoje como teve essa mudança de gestão, ouve-se falar que vai ter, mas nunca aconteceu, e continua se falando que vai acontecer, mas até então eu não vi nada de concreto acontecendo (\#10). 
Portanto, um modelo de gestão que priorize espaços coletivos de informações, troca de saberes, associado ao conhecimento teórico e prático sobre saúde mental, favorece a implantação do apoio matricial (Campos e Domitti, 2007). De um lado, os entrevistados destacaram a importância do trabalho na APS; dois deles (\#6 e \#9), inclusive, sinalizaram que isso possibilitaria a redução da demanda de atendimento; de outro, profissionais ressaltaram que com isso também acabavam acolhendo demandas equivocadas de encaminhamentos realizados pela rede, a exemplo do que um estudo encontrou (Minozzo e Costa, 2013).

Ainda quanto à organização do apoio matricial, os profissionais indicaram ações específicas a serem adotadas pela gestão, com base em suas experiências anteriores. Por exemplo, vários trabalhadores entendiam que a função de ativador de rede deveria ser retomada. Além disso, havia a necessidade da manutenção de condições favoráveis de trabalho que estimulassem os profissionais e desburocratizassem os processos de trabalho.

Foi idiotice tirar a função de ativador de rede, porque nós estamos tão embebidos pelo serviço, a gente entra lá dentro e quase não sai, muita coisa acontece. O ativador de rede é aquele cara que fala assim: 'ei galera, vem embora pra cá', entende? Eu acho que isso faz muita falta, eu acho que foi uma ideia fantástica do Ministério e que os municípios deviam seguir, porque é essa pessoa que conseguia fazer com que as equipes se reunissem (\#4).

A figura do ativador de rede foi uma iniciativa da segunda fase do Projeto Percursos Formativos da Rede de Atenção Psicossocial (RAPS): Engrenagens da Educação Permanente na RAPS (Brasil, 2016). Neste projeto, o Ministério da Saúde custeava o profissional para desempenhar o papel de ativador de rede que norteava sua atuação pela metodologia de roda de conversa. Segundo relatos de \#7, \#8, \#4, \#6 e \#10, essa atividade foi cancelada em 2017 com a mudança de gestão.

A ideia de um ativador de rede foi destacada de diferentes formas pelos trabalhadores, ainda que todos concordassem tratar-se de uma diretriz a ser definida pela gestão. Alguns indicaram que deveria haver uma equipe específica de profissionais para realizar o apoio matricial; outros que deveria existir uma pessoa responsável para articular a rede e favorecer o apoio matricial do ponto de vista logístico e técnico; e ainda uma última proposta concebia a divisão dos usuários por territórios e que deveria haver um profissional de referência para cada território.

Ao considerarem aspectos e ações das equipes para efetivar a reorganização da atenção, os profissionais destacaram a necessidade de empoderamento dos trabalhadores que, mediante sua identificação e motivação para o trabalho em 
saúde mental, poderiam fazer do apoio matricial uma rotina do seu cotidiano de trabalho e utilizá-lo como uma ferramenta de cuidado, como encontrado em outro estudo (Pinto et al., 2012).

Conjuntamente, entende-se que as propostas levantadas pelos profissionais para que o apoio matricial possa atingir suas potencialidades requerem uma revisão dos processos de trabalho de gestão e da clínica. Tal modificação é permeada por desafios e obstáculos, sendo os principais aqueles vinculados à organização dos processos de trabalho e ao desconhecimento de como operacionalizar o apoio matricial (Campos e Domitti, 2007; Ballarin, Blanes e Ferigato, 2012; Jorge et al., 2015).

Em um cenário de pouca autonomia do trabalhador em saúde, Franco e Merhy (2012) entendem o trabalhador como sujeito principal, numa perspectiva do trabalho vivo, conceito que se transfere para a assistência da saúde mental mediante a valorização das tecnologias leves, definidas como ações vinculadas à escuta e construção de vínculo. Portanto, uma lógica em que o trabalhador direciona o caminho do cuidado, com base na escuta qualificada do usuário e não somente nos protocolos (Franco e Merhy, 2012). O trabalhador passa a ter o controle do seu próprio trabalho, construído-o em ato na interação com o usuário (Franco e Merhy, 2012).

Infere-se que a prática cotidiana do profissional de CAPS oferecia, a partir do direcionamento do trabalho vivo, níveis consideráveis de liberdade. Contudo, com base nos relatos dos entrevistados, percebeu-se que a descontinuidade das ações (ocasionadas pela mudança de gestão) e o baixo empoderamento dos profissionais limitavam a implementação de práticas inovadoras e criativas. Mesmo assim, os achados apontaram que, para além de um arranjo organizacional, o apoio matricial se apresentou como uma estratégia ordenadora do cuidado psicossocial, já que possibilitava mudanças na equipe quanto a sua percepção do usuário, favorecia ações no território, construía um cuidado na perspectiva psicossocial e organizava o fluxo da saúde mental na atenção básica.

\section{Considerações finais}

Segundo os achados, os profissionais manifestaram uma compreensão acerca do apoio matricial bastante alinhada às definições conceituais adotadas pela legislação que norteia a Política Nacional de Saúde Mental (Brasil, 2001), refletindo trajetórias profissionais de investimento e especialização nessa área. Porém, embora partindo de um mesmo ideário sobre o apoio matricial, os profissionais de CAPS mostraram diferentes posições diante das propostas de organização do apoio matricial, indicando obstáculos e experiências diversas. 
Assim, uma parte dos profissionais creditava à gestão toda a responsabilidade de operacionalização do apoio matricial, enquanto outros se percebiam como atores desse processo e sinalizavam a importância da construção de processos de trabalho que fortalecessem essa prática no seu cotidiano profissional. Essa construção remete à ideia de emancipação do profissional como responsável pelo produto do seu trabalho, na perspectiva do trabalho vivo, que se concretiza na relação com o usuário, a equipe e a rede (Franco e Merhy, 2012). Aliou-se a isso uma compreensão de gestão baseada na dialogicidade, no qual o trabalho constrói um coletivo implicado com a proposta do apoio matricial, priorizando o usuário.

Nesse sentido, definir o apoio matricial como estratégia de ordenação do cuidado psicossocial em saúde mental implica a superação de vários obstáculos vinculados à gestão dos processos de trabalhos e a apropriação reflexiva da metodologia pelas equipes de saúde. Os achados também indicaram que muitos profissionais, ainda que restritos pelo baixo apoio da gestão e da falta de recursos, buscavam discutir e desenvolver modos possíveis de adaptar e modificar seu trabalho na perspectiva do apoio matricial e do cuidado territorializado, baseando-se em experiências exitosas de articulação de rede.

Este estudo buscou contribuir para cobrir uma lacuna no que concerne ao olhar voltado para o profissional de saúde mental de CAPS, contemplando o contexto do município de Imperatriz (MA). O recorte gera limitações ao mesmo tempo que abre novas possibilidades, pois reflete as particularidades e recorrências quanto à estratégia do apoio matricial em uma região do país pouco abordada nos estudos da área (Pinho, Souza e Esperidião, 2018). Além disso, o presente estudo não abordou a perspectiva dos gestores e usuários quanto ao cuidado implementado a partir do apoio matricial, sendo que futuros trabalhos poderiam ampliar as reflexões sobre a implementação e a efetividade da estratégia.

O apoio matricial como ordenador do cuidado psicossocial no território ganha maior significância no cenário atual, de recentes retrocessos da política de saúde mental que reforçam a convivência do modelo psicossocial com o modelo biomédico-hospitalocêntrico (Sousa e Jorge, 2019). Pode-se inferir que o fortalecimento de estratégias como o apoio matricial seria um instrumento de enfrentamento desse retrocesso, pois no presente estudo o apoio matricial foi visto como facilitador do cuidado em saúde mental na perspectiva psicossocial, uma vez que favorecia o trabalho em equipe e ampliava a visão dos profissionais quanto às possibilidades de intervenção, ao fomentar ações no território e a construção de um cuidado respeitando as diversas dimensões do usuário. 


\section{APOYO MATRICIAL COMO ESTRATEGIA DE ORDENACIÓN DEL CUIDADO EN SALUD MENTAL}

Resumen Este es un estudio cualitativo y transversal, con el objetivo de analizar la perspectiva de los profesionales de los centros de atención psicosocial sobre el apoyo matricial como estrategia de cuidado psicosocial en salud mental. Han sido utilizadas diez entrevistas semiestructuradas con profesionales de servicios de salud mental del municipio de Imperatriz, en el estado de Maranhão, Brasil. Se concluyó que eses profesionales comprenden el apoyo matricial como herramienta indispensable para la organización del cuidado psicosocial, pero este aún es utilizado de modo incipiente en su cotidiano laboral frente a desafíos relacionados a: la coexistencia de los modelos psicosocial y biomédico; falta de condiciones laborales; falta de educación continua y permanente de la red de atención; burocratización y verticalización de las acciones de la gestión; y motivación para el trabajo entre los equipos. Algunas vivencias exitosas de apoyo matricial para esos trabajadores resultaron de la cogestión de los procesos de trabajo entre profesionales y usuarios. Se recomienda que haya un claro direccionamiento del trabajo por parte de la gestión, con la definición de un equipo de matriciadores y una planificación para su realización, construyendo procesos de trabajo que favorezcan tal práctica.

Palabras clave apoyo matricial; sistemas de apoyo psicosocial; servicios de salud mental.

\section{Colaboradores}

Marlene Costa Lima foi responsável pela conceptualização do estudo, revisão de literatura, coleta de dados, análise dos dados, redação da primeira versão e aprovação da versão final do manuscrito; Tonantzin Ribeiro Gonçalves, pela conceptualização do estudo, revisão de literatura, análise e discussão dos resultados, redação e aprovação da versão final do manuscrito.

\section{Financiamento}

Não recebeu financiamento institucional. 


\section{Referências}

ANJOS FILHO, Nilton C. D.; SOUZA, Ana M. P. D. A percepção sobre o trabalho em equipe multiprofissional dos trabalhadores de um centro de atenção psicossocial em Salvador, Bahia, Brasil. Interface: Comunicação, Saúde, Educação, Botucatu, v. 21, n. 60, p. 63-76, 2017.

BALLARIN, Maria L. G. S.; BLANES, Lara D. S.; FERIGATO, Sabrina H. Apoio matricial: um estudo sobre a perspectiva de profissionais da saúde mental. Interface: Comunicação, Saúde, Educação, Botucatu, v. 16, n. 42, p. 767-778, 2012.

BARDIN, Laurence. Análise de conteúdo. 10. ed. Lisboa: Edições 70 , 2009.

BISPO JÚNIOR, José P. B.; MOREIRA, Diane C. Núcleos de apoio à saúde da família: concepções, implicações e desafios para o apoio matricial. Trabalho, Educação e Saúde, Rio de Janeiro, v. 16, n. 2, p. 683-702, 2018.

BONFIM, Iris G. et al. Apoio matricial em saúde mental na atenção primária à saúde: uma análise da produção científica e documental. Interface: Comunicação, Saúde, Educação, Botucatu, v. 17, n. 45, p. 287-300, 2013.

BRASIL. Lei n. 10.216, de 6 de abril de 2001. Dispõe sobre a proteção e os direitos das pessoas portadoras de transtornos mentais e redireciona o modelo assistencial em saúde mental. Diário Oficial da República Federativa do Brasil, Poder Executivo, Brasília, DF, 9 abr. 2001. Disponível em: <http://www.planalto. gov.br/ccivil_03/leis/leis_2001/110216.htm>. Acesso em: 14 ago. 2019.

BRASIL. Ministério da Saúde. Secretaria de Atenção à Saúde. Departamento de Ações Estratégicas. Coordenação Geral de Saúde Mental. Reforma psiquiátrica e política de saúde mental no Brasil. Documento apresentado à Conferência Regional de Reforma dos Serviços de Saúde Mental: 15 anos depois de Caracas. Brasília: Ministério da Saúde, 2005.

BRASIL. Ministério da Saúde. Portaria GMn . 154, de 24 de janeiro de 2008. Cria os Núcleos de Apoio à Saúde da Família-Nasf. Brasília: Ministério da Saúde, 2008.

BRASIL. Ministério da Saúde. Secretaria de Atenção à Saúde. Núcleo Técnico da Política Nacional de Humanização. HumanizaSUS: documento base para gestores e trabalhadores do SUS. 4. ed. Brasília: Ministério da Saúde, 2010.

BRASIL. Ministério da Saúde. Conselho Nacional de Saúde. Resolução n. 466/2012. Aprova diretrizes e normas regulamentadoras de pesquisas envolvendo seres humanos. Diário Oficial da República Federativa do Brasil, Poder Executivo, Brasília, DF, 12 dez. 2012. Disponível em: <http://bvsms.saude.gov.br/ bvs/saudelegis/cns/2013/res0466_12_12_2012. html>. Acesso em: 14 ago. 2019.

BRASIL. Ministério da Saúde. Secretaria de Atenção à Saúde. Departamento de Ações Estratégicas. Coordenação Geral de Saúde Mental, Álcool e Outras Drogas. Saúde mental no SUS: cuidado em liberdade, defesa de direitos e rede de atenção psicossocial. Relatório de Gestão 2011-2015. Brasília: Ministério da Saúde, 2016.

BRASIL. Ministério da Saúde. DATASUS. TabNet-Ministério da Saúde, 2018. Disponível em: <http://tabnet.datasus.gov.br/tabdata/ cadernos/ma.htm > . Acesso em: 28 maio 2019.

CAMPOS, Gastão W. S.; DOMITTI, Ana C. Apoio matricial e equipe de referência: uma metodologia para gestão do trabalho interdisciplinar em saúde. Cadernos de Saúde Pública, Rio de Janeiro, v. 23, n. 2, p. 399-407, 2007.

CAMPOS, Gastão W. S. et al. A aplicação da metodologia Paideia no apoio institucional, no apoio matricial e na clínica ampliada. Interface: Comunicação, Saúde, Educação, Botucatu, v. 18, n. 1, p. 993-985, 2014.

CHIAVERINI, Dulce H. Guia prático de matriciamento em saúde mental. Brasília: Ministério da Saúde, Centro de Estudo e Pesquisa em Saúde Coletiva, 2011. 
COSTA, Pedro H. A.; COLUGNATI, Fernando A. B.; RONZANI, Telmo M. Avaliação de serviços em saúde mental no Brasil: revisão sistemática da literatura. Ciência \& Saúde Coletiva, Rio de Janeiro, v. 20, n. 10, p. 3.243-3.253, 2015.

DISTRITO FEDERAL. Secretaria de Estado de Saúde. Pactuação interfederativa 2017-2021: caderno de diretrizes, objetivos, metas e indicadores. Brasília: Secretaria de Atenção à Saúde, 2016. Disponível em: <http://www.saude. df.gov.br/wp-conteudo/uploads/2017/11/ PACTUACAO-INTERFEDERATIVA-2017-2021. pdf $>$. Acesso em: 28 maio 2019.

FOY, Robbie et al. Meta-analysis: effect of interactive communication between collaborating primary care physicians and specialists. Annals of Internal Medicine, Philadelphia, v. 152, n. 4, p. 247-258, 2010.

FRANCO, Túlio B.; MERHY, Emerson E. Cartografias do trabalho e cuidado em saúde. Tempus Actas de Saúde Coletiva, Brasília, v. 6, n. 2, p. 151-163, 2012.

IGLESIAS, Alexandra; AVELLAR, Luziane Z. Apoio matricial: um estudo bibliográfico. Ciência \& Saúde Coletiva, Rio de Janeiro, v. 19, n. 9, p. 3.791-3.798, 2014.

IMPERATIZ. Prefeitura. 2018. Disponível em: $<$ http://www.imperatriz.ma.gov.br/portal/ imperatriz/a-cidade.html $>$. Acesso em: 28 maio 2019.

JORGE, Maria S. B. et al. Promoção da saúde mental: tecnologias do cuidado - vínculo, acolhimento, corresponsabilização e autonomia. Ciência \& Saúde Coletiva, Rio de Janeiro, v. 16, n. 7, p. 3.051-3.059, 2011.

JORGE, Maria S. B. et al. Apoio matricial, projeto terapêutico singular e produção do cuidado em saúde mental. Texto \& Contexto Enfermagem, Florianópolis, v. 24, n. 1, p. 112-120, 2015.

KELLY, Brian J. et al. Shared care in mental illness: a rapid review to inform implementa- tion. International Journal of Mental Health Systems, s.1., v. 5, n. 31, p. 1-12, 2011.

MERHY, Emerson E. et al. Redes vivas: multiplicidades girando as existências, sinais da rua - implicações para a produção do cuidado e a produção do conhecimento em saúde. Saúde para Debate, Rio de Janeiro, v. 52, p. 153-164, 2014.

MINAYO, Maria C. S. O desafio do conhecimento: pesquisa qualitativa em saúde. 12. ed. São Paulo: Hucitec; Rio de Janeiro: Abrasco, 2010.

MINOZZO, Fabiane; COSTA, Ileno I. Apoio matricial em saúde mental entre CAPS e saúde da família: trilhando caminhos possíveis. PsicoUSF, Itatiba, v. 18, n. 1, p. 151-159, 2013.

OLIVEIRA, Mônica M.; CAMPOS, Gastão W. S. Apoio matricial e institucional: analisando suas construções. Ciência \& Saúde Coletiva, Rio de Janeiro, v. 20, n. 1, p. 229-238, 2015.

PATEL, Vikram et al. The Lancet Commission on global mental health and sustainable development. Lancet, London, v. 392, n. 10.157, p. 1.553-1.598, 2018.

PINHO, Eurides S. S.; SOUZA, Adrielle C. S.; ESPERIDIÃO, Elizabeth. Processos de trabalho dos profissionais dos centros de atenção psicossocial: revisão integrativa. Ciência \& Saúde Coletiva, Rio de Janeiro, v. 23, n. 1, p. 141-152, 2018.

PINTO, Antonio G. A. et al. Apoio matricial como dispositivo do cuidado em saúde mental na atenção primária: olhares múltiplos e dispositivos para resolubilidade. Ciência \& Saúde Coletiva, Rio de Janeiro, v. 17, n. 3, p. 653-660, 2012.

PRATA, Nina I. S. S. et al. Saúde mental e atenção básica: território, violência e o desafio das abordagens psicossociais. Trabalho, Educação e Saúde, Rio de Janeiro, v. 15, n. 1, p. 33-53, 2017.

SANTOS, Élem G.; SIQUEIRA, Marluce M. Prevalência dos transtornos mentais na 
população adulta brasileira: uma revisão sistemática de 1997 a 2009. Jornal Brasileiro de Psiquiatria, Rio de Janeiro, v. 59, n. 3, p. 238-246, 2010.

SOUSA, Fernando S. P.; JORGE, Maria S. B. $O$ retorno da centralidade do hospital psiquiátrico: retrocessos recentes na política de saúde mental. Trabalho, Educação e Saúde, Rio de Janeiro, v. 17, n. 1, e0017201, 2019.

SUNDFELD, Ana C. Clínica ampliada na atenção básica e processos de subjetivação: relato de uma experiência. Physis: Revista de Saúde Coletiva, Rio de Janeiro, v. 20, n. 4, p. 1.079-1.097, 2010.

VIANA, Mônica M. D. O.; CAMPOS, Gastão W. S. Formação Paideia para o apoio matricial: uma estratégia pedagógica centrada na reflexão sobre a prática. Cadernos de Saúde Pública, Rio de Janeiro, v. 34, n. 8, e00123617, 2018.

WORLD HEALTH ORGANIZATION (WHO). Depression and other common mental disorders: global health estimates. Genebra: WHO, 2017. (N. WHO/MSD/MER/2017.2). 